\title{
Comportamento ingestivo de bovinos Nelore confinados com diferentes níveis de substituição de silagem de sorgo por cana-de-açúcar ou bagaço de cana amonizado com ureia
}

\author{
Ingestive behavior of feedlot Nellore cattle with different levels of \\ substitution of sorghum silage for sugarcane \\ or sugarcane bagasse ammoniated with urea
}

\author{
Ricardo carvalho de Barros, ${ }^{*}$ Vicente Ribeiro Rocha Júnior, ${ }^{* *}$ Edílson Paes Saraiva, ${ }^{\star \star *}$ Gustavo Almeida Mendes, ${ }^{\star \star}$ \\ Gustavo Chamon de Castro Meneses, ${ }^{* * *}$ Célio Roberto de Oliveira, ${ }^{* * * *}$ Wéder Jânsen Barbosa Rocha, ${ }^{* * * *}$ \\ Ana Cássia Rodrigues de Aguiar, ${ }^{* * * *}$ Carlos César Rodrigues dos Santos ${ }^{* * * *}$
}

\begin{abstract}
Resumo
Objetivou-se avaliar o comportamento ingestivo de bovinos Nelore submetidos a diferentes níveis de substituição de silagem de sorgo por cana-de-açúcar ou bagaço de cana amonizado com ureia. Foram confinados 35 animais machos não castrados, distribuídos em sete tratamentos: $100 \%$ silagem de sorgo; $70 \%$ de silagem de sorgo + 30\% de cana-de-açúcar; $30 \%$ de silagem de sorgo + 70\% de cana-de-açúcar; $100 \%$ de cana-de-açúcar; $70 \%$ de silagem de sorgo + 30\% de bagaço de cana amonizado com ureia; $30 \%$ de silagem de sorgo $+70 \%$ de bagaço de cana amonizado com ureia e $100 \%$ de bagaço de cana amonizado com ureia. Todos os animais foram submetidos a observação visual para avaliação do comportamento ingestivo aos 15, 30 e 50 dias do período experimental. O aumento do teor de cana na dieta em substituição à silagem de sorgo, não provocou alterações nos tempos de alimentação, ruminação e ócio dos animais. Já a substituição da silagem de sorgo por bagaço de cana amonizado com ureia provocou alterações no comportamento ingestivo, reduzindo o tempo de alimentação e aumentando o tempo de ruminação dos animais. O número de ciclos de ruminação e a duração destes ciclos foram afetados por ambos volumosos substitutos.
\end{abstract}

Palavras-chave: ócio, ruminação, tempo de alimentação.

\begin{abstract}
The objective of this trial was to evaluate the ingestive behavior of Nelore bovines subjected to different levels of substitution of sorghum silage for sugarcane or sugarcane bagasse ammoniated with urea. There were confined 35 young bulls distributed in 7 treatments: $100 \%$ of sorghum silage; $70 \%$ of sorghum silage $+30 \%$ of sugarcane; $30 \%$ of sorghum silage $+70 \%$ of sugarcane; $100 \%$ of sugarcane; $70 \%$ of sorghum silage $+30 \%$ of sugarcane bagasse ammoniated with urea; $30 \%$ of sorghum silage + $70 \%$ of sugarcane bagasse ammoniated with urea and $100 \%$ of sugarcane bagasse ammoniated with urea. All animals were visually observed to evaluate their ingestive behavior at 15, 30 and 50 days of the experimental period. The increased content of sugarcane in the diet of feedlot Nellore, at different levels of substitution of sorghum silage, did not involve changes in the times of feeding, rumination and idleness of the animals. Already the replacement of sorghum silage by sugarcane bagasse ammoniated with urea led to changes in ingestive behavior, reducing the feeding time and increasing the ruminating time the animals. The number of cycles of rumination and duration of these cycles were affected by both bulky substitutes.
\end{abstract}

Keywords: idleness, rumination, time of feeding.

\section{Introdução}

O tempo gasto na ruminação pelos bovinos está diretamente relacionado com a quantidade de fibra presente na dieta; assim como a redução do tamanho de partícula, hidratação do alimento, exposição de nutrientes solúveis para fermentação e colonização microbiana são atividades básicas para o processo de digestão (Van Soest, 1994). Segundo vários autores (Marques et al., 2006; Pereira et al., 2007; Pereira et al., 2009), o período de ruminação pode

\footnotetext{
* Programa de Pós-Graduação em Produção Vegetal da UNIMONTES. Autor para correspondência: Vicente Ribeiro Rocha Júnior. Av. Reinaldo Viana 2630, Bico da Pedra, Campus Universitário, Janaúba/MG, CEP 39440-000. E-mail: vicente.rocha@unimontes.br

** Programa de Pós-Graduação em Zootecnia da UNIMONTES.

*** Programa de Pós-Graduação em Zootecnia da Universidade Federal da Paraíba.

**** Programa de Pós-Graduação em Zootecnia da UFV.

***** Departamento de Ciências Agrárias da UNIMONTES/Curso de Zootecnia.
} 
aumentar em função de um maior consumo de alimentos contendo elevada proporção de constituintes fibrosos.

A fibra é o componente da dieta que é responsável pela sensação de enchimento do rúmen, sendo que os tempos de ingestão e ruminação são proporcionais à quantidade total de parede celular ingerida (Van Soest, 1994). Por outro lado, não é só a fibra a responsável pela sensação de saciedade do animal. Teores elevados de concentrado na ração e menores níveis de fibra também podem resultar em menor consumo de matéria seca, uma vez que as exigências energéticas dos ruminantes poderão ser obtidas com nível de consumo mais baixo (Gonçalves et al., 2001). Esses fatores sugerem que a máxima eficiência da alimentação nos ruminantes em confinamento deverá propiciar um equilíbrio nutricional entre a quantidade de fibra e energia, para que o excesso de um destes componentes não provoque a sensação de saciedade do animal, levando ao baixo aproveitamento do outro componente.

O comportamento ingestivo de novilhos de corte alimentados com dietas à base de bagaço de cana-de-açúcar tratado sob pressão e vapor, avaliando-se a substituição deste por bagaço de cana-de-açúcar obtido por difusão ou bagaço de cana obtido por moagem, foi testado por Rabelo et al. (2001). A maior inclusão de bagaço de cana obtido por difusão determinou tendência de aumento no tempo gasto para ingestão, ruminação e mastigação e redução do tempo em ócio; a adoção do bagaço de cana obtido por moagem determinou maior consumo de MS e menor tempo despendido com as atividades de ingestão e mastigação. A extração mais eficiente de sólidos solúveis pelo método de difusão sugere menores taxas de passagem e de digestão que justifiquem o comportamento observado.

Objetivou-se com este trabalho avaliar o comportamento ingestivo de novilhos Nelore em confinamento submetidos a diferentes níveis de substituição da silagem de sorgo por canade-açúcar ou bagaço de cana-de-açúcar amonizado com ureia.

\section{Material e métodos}

O experimento foi conduzido na Fazenda Experimental da Universidade Estadual de Montes Claros - Unimontes, localizada no município de Janaúba, Minas Gerais, de março a maio de 2007. Utilizaram-se 35 novilhos não castrados da raça Nelore, com idade média de 24 meses e peso médio inicial de 448,2 $\pm 26,52 \mathrm{~kg}$. Os animais foram distribuídos em sete baias coletivas de confinamento, com área de $50 \mathrm{~m}^{2}$ cada (5 metros de largura por 10 metros de comprimento), parcialmente cobertas, contendo cochos de concreto $(1,0 \mathrm{~m}$ linear / animal) e bebedouros regulados por torneira-boia, sendo cinco animais para cada tratamento utilizado, perfazendo uma área de $10 \mathrm{~m}^{2} /$ animal.

Os tratamentos foram definidos considerando-se a fração volumosa das dietas: $100 \%$ de silagem de sorgo; $70 \%$ de silagem de sorgo + 30\% de cana-de-açúcar; 30\% de silagem de sorgo + 70\% de cana-de-açúcar; $100 \%$ de cana-de-açúcar; $70 \%$ de silagem de sorgo $+30 \%$ de bagaço de cana-deaçúcar amonizado com ureia; $30 \%$ de silagem de sorgo + $70 \%$ de bagaço de cana-de-açúcar amonizado com ureia; $100 \%$ de bagaço de cana-de-açúcar amonizado com ureia. Esses percentuais foram estabelecidos em relação à matéria seca dos diferentes volumosos. Foi utilizado um delineamento experimental inteiramente casualizado, com cinco repetições por tratamento.

Antes de se iniciar o período experimental, que teve duração de 50 dias, os animais foram vermifugados com produto anti-helmíntico à base de ivermectina e passaram por um período de adaptação às rações experimentais e instalações, com duração de 15 dias.

O bagaço de cana-de-açúcar utilizado, acrescido de $20 \%$ de ponta de cana na matéria natural, foi adquirido de produtores de aguardente da região. Após a desintegração em picadeira estacionária, o bagaço de cana-de-açúcar foi submetido à amonização com o uso de $5 \%$ de ureia e $2 \%$ de soja grão moída, na base da matéria seca, e armazenado em silo de superfície, durante dois meses antes de sua utilização. A mistura foi envolvida por lonas de polietileno com espessura de 0,20 $\mathrm{mm}$, sendo que após o enchimento, o silo foi vedado com fitas adesivas e terra. A cana-de-açúcar, in natura, foi cortada e picada diariamente, em picadeira estacionária, momentos antes do fornecimento aos animais no cocho.

As rações experimentais foram formuladas segundo Valadares Filho et al. (2006), sendo fornecidas diariamente em quantidade para proporcionar sobras de $10 \%$, garantindo, assim, consumo ad libitum. Em função da variação de peso dos animais e do consumo voluntário, as quantidades de alimento foram reajustadas sempre que necessário, sendo as sobras dos cochos pesadas diariamente. O mesmo concentrado foi fornecido em proporção fixa de 1,2\% do peso corporal, com base na matéria natural dos concentrados, em todos os tratamentos. Os animais foram alimentados duas vezes ao dia, sendo a metade da ração oferecida pela manhã e a outra metade à tarde.

Os cochos foram limpos todos os dias pela manhã, sempre no mesmo horário (6 horas), momento no qual as sobras foram pesadas. Os alimentos volumosos e concentrados foram rigorosamente pesados e fornecidos no cocho, sendo em seguida misturados.

As rações foram calculadas para serem isonitrogenadas, sendo que a ureia foi utilizada para corrigir os níveis de proteína bruta dos diferentes volumosos, adicionada nas seguintes proporções da matéria natural: 0,40\%, 0,58\%, $0,82 \%, 1,00 \%, 0,34 \%, 0,18 \%$ e $0,00 \%$. A quantidade de ureia correspondente para cada tratamento foi fornecida e misturada no cocho aos demais ingredientes da ração.

A composição do concentrado utilizado em todos os tratamentos foi constituída de $88,74 \%$ de fubá de milho, $10,33 \%$ de farelo de soja e $0,69 \%$ de núcleo mineral (Níveis de Garantia: 16\% P, 21\% Ca, 3\% Mg, 3,2\% S, 50 ppm Co, 1901 ppm Cu, 167 ppm I, 2000 ppm Mn, 31 ppm Se e 6498 ppm $\mathrm{Zn})$ e $0,24 \%$ de sal comum ( $\mathrm{NaCl})$.

Amostras dos alimentos e das sobras de cada tratamento foram coletadas semanalmente e encaminhadas para análise no Laboratório de Análise de Alimentos, do Departamento de Ciências Agrárias da UNIMONTES, em Janaúba, após serem submetidas à pré-secagem a $55^{\circ} \mathrm{C}$ em estufas de ventilação forçada por 72 horas, moídas em moinhos de facas em peneira de $1 \mathrm{~mm}$ e armazenadas em recipientes de vidro. 
A composição química dos alimentos (Tabela 1) e das rações experimentais (Tabela 2) foram avaliadas segundo métodos usualmente utilizados e descritos na literatura. Análises de matéria seca proteína bruta, extrato etéreo, matéria orgânica e cinzas, foram realizadas conforme procedimento descrito pela AOAC (1990). A fibra em detergente neutro, fibra em detergente ácido e a lignina foram estimadas seguindo o método de Van Soest et al. (1991). Os teores de compostos nitrogenados insolúveis em detergente neutro (NIDN) e ácido (NIDA), foram estimados nos resíduos obtidos após extrações das amostras nos detergentes neutro e ácido, respectivamente, por intermédio do método de Kjeldahl (AOAC, 1990). A partir da determinação do NIDN procedeuse à correção da fibra em detergente neutro para proteínas. Estimou-se também a digestibilidade in vitro da matéria seca (DIVMS) para os alimentos constituintes das dietas pelo método de Tilley e Terry (1963).

Tabela 1: Composição química dos ingredientes com base na matéria seca (MS) para o bagaço de cana amonizado com ureia (BAU), cana-de-açúcar (CAN), silagem de sorgo (SS), milho (MI) e farelo de soja (FS)

\begin{tabular}{cccccc}
\hline & BAU & CAN & SS & MI & FS \\
\hline MS & 43,80 & 25,69 & 25,61 & 89,61 & 89,66 \\
MO & 93,24 & 97,2 & 92,91 & 98,54 & 95,84 \\
PB & 13,21 & 3,42 & 9,30 & 10,58 & 45,92 \\
EE & 0,23 & 0,97 & 2,95 & 5,87 & 3,27 \\
MM & 6,76 & 2,80 & 7,09 & 1,46 & 4,16 \\
FDN & 75,72 & 53,87 & 69,56 & 16,97 & 16,12 \\
FDA & 56,64 & 32,96 & 40,81 & 4,33 & 11,98 \\
FDNp & 73,89 & 52,77 & 69,27 & 15,29 & 16,08 \\
Lignina & 8,79 & 6,28 & 9,41 & 1,54 & 4,31 \\
NIDN & 0,85 & 0,18 & 0,50 & 0,39 & 0,32 \\
NIDA & 0,20 & 0,15 & 0,20 & 0,12 & 0,06 \\
DIVMS & 51,98 & 64,84 & 57,97 & 83,55 & 84,89 \\
\hline
\end{tabular}

MS = Matéria Seca; MO = Matéria Orgânica; PB = Proteína Bruta; EE = Extrato Etéreo; $M M=$ Matéria Mineral; $F D N=$ Fibra em Detergente Neutro; FDA = Fibra em Dtergente Ácido; FDNp = Fibra em Detergente Neutro corrigida para proteína; NIDN = Nitrogênio Insolúvel em Detergente Neutro; NIDA = Nitrogênio Insolúvel em Detergente Ácido; DIVMS = digestibilidade in vitro da matéria seca.

Tabela 2: Composição química das rações relativas a cada tratamento em porcentagem da matéria seca

\begin{tabular}{ccccccccc}
\hline Tratamentos & $\mathrm{MS}^{1}$ & $\mathrm{FDN}^{2}$ & $\mathrm{FDA}^{3}$ & $\mathrm{~PB}^{4}$ & $\mathrm{EE}^{5}$ & $\mathrm{MM}^{6}$ & $\mathrm{CNF}^{7}$ & Lignina $^{2}$ \\
& & & & & & & & \\
\hline T1 & 35,19 & 49,29 & 25,83 & 11,50 & 3,96 & 5,05 & 30,20 & 6,60 \\
T2 & 35,96 & 44,90 & 24,25 & 11,08 & 3,63 & 4,03 & 36,36 & 5,70 \\
T3 & 37,24 & 39,69 & 21,56 & 11,02 & 3,30 & 2,98 & 43,01 & 4,80 \\
T4 & 39,12 & 35,52 & 18,49 & 11,62 & 3,24 & 2,27 & 47,35 & 4,10 \\
T5 & 39,95 & 48,21 & 28,08 & 12,16 & 3,67 & 4,79 & 31,17 & 6,10 \\
T6 & 49,29 & 46,08 & 28,80 & 13,07 & 3,34 & 4,39 & 33,12 & 5,50 \\
T7 & 62,45 & 40,95 & 26,26 & 13,75 & 3,41 & 3,81 & 38,08 & 4,70 \\
\hline
\end{tabular}

T1 = 100\% de silagem de sorgo; T2 = 70\% de silagem de sorgo + 30\% de cana-de-açúcar; T3 = 30\% de silagem de sorgo + 70\% de cana-de-açúcar; T4 = 100\% de cana-de-açúcar; T5 = 70\% de silagem de sorgo $+30 \%$ de bagaço de cana amonizado com ureia; T6 = 30\% de silagem de sorgo $+70 \%$ de bagaço de cana amonizado com ureia e T7 $=100 \%$ de bagaço de cana amonizado com ureia; ${ }^{1} \mathrm{MS}=\mathrm{Matéria}$ Seca; ${ }^{2}$ FDN = Fibra em Detergente Neutro; ${ }^{3} \mathrm{FDA}=$ Fibra em Dtergente Ácido; ${ }^{4} \mathrm{~PB}=$ Proteína Bruta; ${ }^{5} \mathrm{EE}$ $=$ Extrato Etéreo; ${ }^{6} \mathrm{MM}=$ Matéria Mineral; ${ }^{7} \mathrm{CFN}=$ Carboidratos Não Fibrosos.
Os 35 animais foram submetidos a observação visual para avaliação do comportamento ingestivo aos 15, 30 e 50 dias do período experimental, durante dois dias consecutivos. Os animais foram observados por três períodos de duas horas as 11 h; 15 às 17 h e 19 às 21 h), medindo-se a média do me mastigações merícicas por bolo ruminal e a média do tempo despendido de mastigação merícica por bolo ruminal, usando-se cronômetro digital. No segundo dia, o comportamento de cada novilho foi determinado visualmente, a intervalos de 10 minutos, durante 24 horas, para determinar o tempo despendido em alimentação, ruminação e ócio.

O número de mastigações merícicas em 24 horas foi obtido mediante a multiplicação do tempo médio de ruminação nas 24 horas do dia pelo número de mastigações merícicas por minuto. O número médio de bolos em 24 horas foi obtido divisão do tempo médio de ruminação, nas 24

As análises estatísticas foram realizadas por intermédio do programa SAS (SAS Institute, 2000). As variáveis foram submetidas a análise de variância e quando significativa $(P<0,05)$, realizou-se o estudo de regressão para os níveis de substituição da silagem de sorgo pela cana-de-açúcar ou bagaço de cana amonizado.

Para os dados relativos aos consumos de matéria seca e nutrientes procedeu-se à análise descritiva dos dados, visto que a alimentação dos animais foi coletiva por tratamento.

\section{Resultados e discussão}

O tempo de alimentação despendido pelos animais não apresentou diferença $(P>0,05)$ em função da substituição da silagem de sorgo por cana-de-açúcar na dieta, tampouco o empo despendido com ruminação (Tabela 3), apesar do sumo de matéria seca ter reduzido gradualmente de 11,98 para $9,06 \mathrm{~kg} / \mathrm{dia}$, com a substituição da silagem de sorgo em $100 \%$ pela cana-de- açúcar. Provavelmente, a maior digestibilidade in vitro da matéria seca da cana $(64,84 \%)$, à presença de um maior teor de açúcares, em relação a silagem de sorgo (57,97\% de DIVMS) e a redução dos teores de FDN na dieta com a inclusão da cana em substituição a silagem, equilibraram os mecanismos físicos e químicos de controle da ingestão de alimentos, e consequentemente, o tempo gasto com alimentação e ruminação. Vale ressaltar que a melhor qualidade da FDN da silagem de sorgo permitiu maior consumo de matéria seca pelos animais. O resultado obtido corrobora os encontrados por Mendonça et al. (2004), que ao avaliarem o comportamento ingestivo de vacas leiteiras submetidas a dietas à base de silagem de milho ou cana-deaçúcar, não assinalaram diferença para os tempos médios despendidos com alimentação e ruminação para as diferentes dietas experimentais. 
Tabela 3: Tempo de alimentação (TA), tempo de ruminação (TR) e tempo de ócio (TO), em minutos, de novilhos Nelore confinados com diferentes níveis de substituição da silagem de sorgo por cana ou bagaço de cana amonizado com ureia (B.A.)

\begin{tabular}{|c|c|c|c|c|c|c|c|}
\hline \multirow{2}{*}{ Variável } & \multirow{2}{*}{ Volumoso } & \multicolumn{4}{|c|}{ Níveis de Substituição, \% } & \multirow{2}{*}{ Média } & \multirow{2}{*}{$\mathrm{CV}^{1}, \%$} \\
\hline & & 0 & 30 & 70 & 100 & & \\
\hline \multirow[b]{2}{*}{ TA } & Cana & & 272,67 & 283,33 & 240,67 & 261,39 & \multirow[b]{2}{*}{13,19} \\
\hline & B.A. & 248,88 & 274,30 & 252,07 & 204,00 & 244,81 & \\
\hline \multirow[b]{2}{*}{ TR } & Cana & & 455,33 & 457,33 & $420,00 \mathrm{~b}$ & 451,61 & \multirow[b]{2}{*}{9,05} \\
\hline & B.A. & 473,78 & 411,70 & 453,40 & $486,67 a$ & 456,39 & \\
\hline \multirow{2}{*}{ TO } & Cana & 71733 & 712 & 699,33 & 779,33 & 727 & \multirow{2}{*}{8,04} \\
\hline & B.A. & & 754 & 734,53 & 749,33 & 738,80 & \\
\hline
\end{tabular}

Médias seguidas por letra diferente na coluna diferem estatisticamente $(p<0,05)$ pelo Teste $F ;{ }^{1} \mathrm{CV}=$ Coeficiente de Variação

Miranda et al. (1999), trabalhando com novilhas leiteiras alimentadas com dietas à base de cana-de-açúcar e utilizando diferentes níveis de NNP e probióticos, não observaram diferença para o tempo despendido na alimentação e ruminação. Neste caso, as dietas tinham o mesmo volumoso, e o teor de cana-de-açúcar na dieta variou de $61,94 \%$ a $81,94 \%$ com base na matéria seca para os diferentes tratamentos.

$\mathrm{Na}$ substituição da silagem de sorgo pelo bagaço de cana amonizado com ureia, no entanto, o comportamento foi quadrático para o tempo de alimentação $(P<0,05)$, sendo, o teor máximo calculado de bagaço de cana-de-açúcar a partir do qual os tempos de alimentação diminuíram de 36,75\% (Figura 1). Já ao se analisar o tempo gasto para ruminação em função da substituição da silagem de sorgo pelo bagaço de cana, o comportamento também foi quadrático, porém, com efeito inverso, com ponto de mínimo ocorrendo a partir da adição de $44,39 \%$ de bagaço de cana-de-açúcar na dieta $(P<0,05)$ (Figura 1). O comportamento apresentado pode ser explicado pelo aumento do teor de FDN na dieta com a adição de bagaço de cana, que provavelmente, ocasionou uma diminuição da taxa de passagem com consequente enchimento ruminal, tendendo a diminuir o tempo de alimentação e a aumentar o tempo de ruminação.

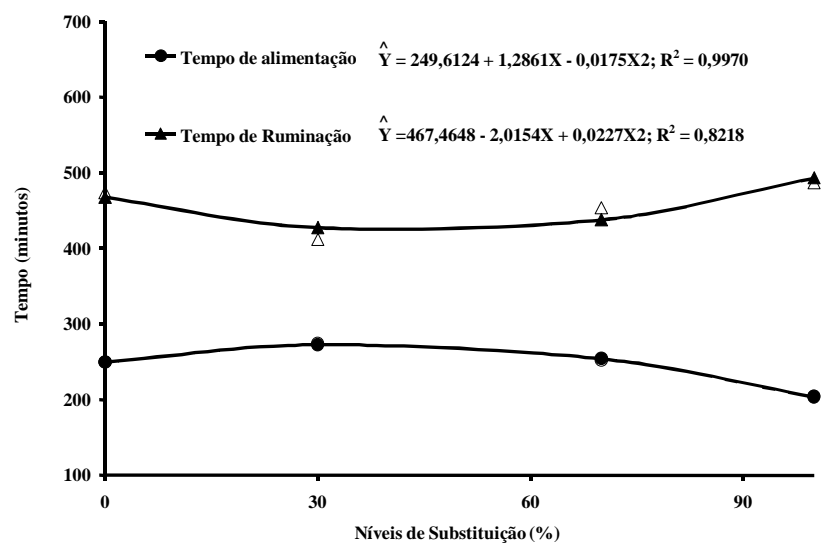

Figura 1: Tempos de alimentação e ruminação de novilhos Nelore confinados com diferentes níveis de substituição da silagem de sorgo por bagaço de cana amonizado com ureia.
Provavelmente o responsável pelo comportamento quadrático para os tempos de ingestão e ruminação seja 0 baixo consumo de matéria seca $(7,65 \mathrm{~kg} /$ animal/dia) apresentado pelos animais, quando o volumoso foi constituído de $100 \%$ de bagaço de cana amonizado. Barros et al. (2010) mostram redução do consumo de matéria seca e de FDN, respectivamente, de 11,98 para $7,65 \mathrm{~kg} / \mathrm{dia}$, e de 5,74 para $2,89 \mathrm{~kg} / \mathrm{dia}$, quando a silagem de sorgo foi substituída em $100 \%$ pelo bagaço de cana na dieta de novilhos em confinamento.

Silva et al. (2005) encontraram redução linear nos tempos de ruminação e alimentação de novilhas confinadas em função do aumento dos níveis de bagaço de mandioca $(5,10,15$ e $20 \%)$ em dietas à base de silagem de capimelefante, sendo que, à medida que se aumentava o teor de bagaço de mandioca, caía o teor de FDN da dieta fornecida. Esses mesmos autores observaram aumento do tempo de ócio à medida que se aumentava o teor de bagaço de mandioca na dieta. A redução no consumo de matéria seca com a inclusão do bagaço ajuda a explicar a diminuição nos tempos de alimentação e ruminação, apesar da queda no teor de FDN da dieta. Entretanto, a qualidade inferior da FDN do bagaço em relação à da silagem respalda este resultado.

Abrahão et al. (2006) também observaram que animais alimentados com feno de tifton despenderam mais tempo em alimentação e menor tempo em ócio que os animais tratados com silagem de sorgo, diferentemente do observado neste experimento, onde os tempos de alimentação e ruminação foram significativamente influenciados com a introdução de bagaço na dieta, o que não afetou o tempo de ócio (Tabela 3). O fato dos efeitos nos tempos de alimentação e ruminação terem sido inversos e relativamente proporcionais (Figura 1) explica o resultado observado para o tempo de ócio. No caso da substituição gradual da silagem de sorgo por cana-de-açúcar, o tempo despendido em ócio também não foi diferente $(P>0,05)$, repetindo o observado para a alimentação e ruminação (Tabela 3). Neste caso, como os tempos de alimentação e ruminação foram semelhantes entre as dietas, também era esperado que os tempos de ócio fossem os mesmos.

Não foi verificado efeito significativo $(P>0,05)$ dos níveis de substituição sob os tempos de mastigação e número de bolos ruminais por dia (Tabela 4). Todavia, a substituição da silagem de sorgo por bagaço de cana amonizado levou à queda nas mastigações merícicas por bolo e tempo de mastigações merícicas por bolo, em relação aos tratamentos onde a cana-de-açúcar foi o volumoso substituto $(P<0,05)$ (Tabela 4).

Mendes Neto et al. (2007), estudando o comportamento ingestivo de novilhas, observaram diminuição no número de mastigações merícicas à medida que se aumentava o teor 
Tabela 4: Tempo total de mastigação (TTM, minutos), mastigações merícicas por dia (MM/ dia), mastigações merícicas por minuto (MM/min.), mastigações merícicas por bolo (MM/bolo), tempo de mastigações merícicas por bolo (TMM/bolo), bolos ruminais por dia (BR/dia) de novilhos Nelore confinados com diferentes níveis de substituição da silagem de sorgo por cana ou bagaço de cana amonizado com ureia (B.A.)

\begin{tabular}{|c|c|c|c|c|c|c|c|}
\hline \multirow{2}{*}{ Variável } & \multirow{2}{*}{ Volumoso } & \multicolumn{4}{|c|}{ Níveis de Substituição, \% } & \multirow{2}{*}{ Média } & \multirow{2}{*}{$C V^{1}, \%$} \\
\hline & & 0 & 30 & 70 & 100 & & \\
\hline \multirow{3}{*}{ TTM } & Cana & & 728 & 740,67 & 660,67 & 712,99 & \multirow{3}{*}{8,33} \\
\hline & & 722,62 & & & & & \\
\hline & B.A. & & 685,90 & 705,47 & 690,67 & 701,16 & \\
\hline \multirow[b]{2}{*}{ MM/dia } & Cana & \multirow[b]{2}{*}{28883,21} & 28353,71 & 29140,14 & 25058,01 & 27858,77 & \multirow[b]{2}{*}{13,87} \\
\hline & B.A. & & 25981,57 & 27385,18 & 28546,87 & 27699,21 & \\
\hline \multirow[b]{2}{*}{$\mathrm{MM} / \mathrm{min}$} & Cana & \multirow[b]{2}{*}{60,88} & 62,07 & 63,78 & 60,05 & 61,69 & \multirow[b]{2}{*}{9,50} \\
\hline & B.A. & & 62,91 & 60,40 & 58,41 & 60,65 & \\
\hline \multirow{3}{*}{ MM/bolo } & Cana & \multirow{3}{*}{61,37} & 61,47 & 63,90 & 57,93 & $61,17 a$ & \multirow{3}{*}{14,69} \\
\hline & & & & & & & \\
\hline & B.A. & & 56,05 & 53,65 & 50,18 & $55,31 b$ & \\
\hline \multirow[b]{2}{*}{ TMM/bolo } & Cana & \multirow[b]{2}{*}{60,53} & 59,07 & 60,70 & 58,05 & $59,59 a$ & \multirow[b]{2}{*}{12,61} \\
\hline & B.A. & & 53.63 & 53,33 & 51.47 & $54.74 b$ & \\
\hline \multirow{3}{*}{ BR/dia } & Cana & & 467.36 & 455,19 & 445.54 & 461.22 & \multirow{3}{*}{15,03} \\
\hline & & 476,79 & & & & & \\
\hline & B.A. & & 468,54 & 510,28 & 571,21 & 506,70 & \\
\hline
\end{tabular}

Médias seguidas por letra diferente na coluna diferem estatisticamente $(p<0,05)$ pelo Teste $F ;{ }^{1} \mathrm{CV}=$ Coeficiente de Variação.

de polpa de citros em substituição ao feno de tifton 85 na dieta dos animais. Provavelmente, a maior degradabilidade da fibra da polpa cítrica permitiu aumento na taxa de passagem e menor necessidade de ruminação. Miranda et al. (1999) não constataram diferença significativa para o número de mastigações merícicas por dia, minuto ou bolo, bem como tempo de mastigações por bolo e número de bolos ruminais por dia ao usarem diferentes níveis de canade-açúcar $(61,94$ e $81,94 \%)$ e fontes de NNP na dieta de novilhas mestiças. Neste caso, as diferenças relacionadas com o nível de cana e a fonte de NNP, entre as dietas experimentais, não implicaram mudanças nessas variáveis do comportamento ingestivo.

Rabelo et al. (2001) verificaram que o aumento do teor de bagaço de cana-de-açúcar obtido por difusão em detrimento ao bagaço obtido pelo método de moagem determinou aumento no tempo gasto para mastigação, gerando redução no tempo de ócio, sugerindo que as menores taxas de passagem e/ou digestão do bagaço que sofreu extração mais eficiente dos sólidos solúveis (método de difusão) justificariam o comportamento ingestivo observado.

Bürger et al. (2000) encontraram tempos de mastigação variando de $368 \mathrm{~min}$./dia (relação volumoso:concentrado de 10:90) a $746 \mathrm{~min} . /$ dia (relação volumoso:concentrado de 70:30), compatíveis aos encontrados neste trabalho, assim como as mastigações merícicas por bolo de 51,47 a 67,36 também o foram. Neste trabalho, a relação volumoso: concentrado nas dietas com $100 \%$ de silagem de sorgo,
$100 \%$ de cana e $100 \%$ de bagaço amonizado foram, respectivamente, de 60:40, 50:50 e 40:60 da matéria seca, o que não afetou o tempo de mastigação, possivelmente em virtude das diferenças nos teores de FDN, qualidade da fibra e consumo de matéria seca entre as dietas experimentais. A associação destes fatores ajuda a explicar a semelhança nos tempos de mastigação para as diferentes dietas (Tabela 4), visto que, as dietas com maior proporção de silagem de sorgo apresentaram maior teor de FDN e maior consumo, em razão da melhor qualidade da fibra deste volumoso. Por outro lado, as dietas com maior percentual de cana ou bagaço de cana, apesar de terem menor teor de FDN, permitiram menor consumo, o que pode ser justificado pela pior qualidade da fibra destes volumosos.

Os resultados apresentados na Tabela 5 sugerem uma tendência de aumento do tempo gasto para o consumo de FDN quando se aumentou o teor de bagaço de cana amonizado na dieta. O tempo gasto de ruminação da matéria seca variou de 39,39 a 63,62 min./kg de MS. Infere-se que, à medida que se elevava os níveis de substituição com o bagaço de cana, havia uma tendência de aumento no tempo gasto de ruminação por $\mathrm{kg}$ de MS ingerida, seguindo esta mesma tendência para o tempo gasto de ruminação por $\mathrm{kg}$ de FDN consumida, tanto para substituição com bagaço como para substituição com cana. Todavia, os resultados sugerem que estas tendências foram mais pronunciadas quando a substituição da silagem de sorgo foi pelo bagaço de cana amonizado com ureia (Tabela 5). Mais uma vez, a qualidade inferior da fibra, especialmente do bagaço de cana amonizado com ureia, pode ter interferido nos tempos para o consumo de MS e FDN.

Com relação ao tempo de mastigação, infere-se que houve tendência de aumento à medida que se elevava o nível de substituição, variando de $60,32 \mathrm{~min} . / \mathrm{kg}$ de MS para o tratamento com $100 \%$ de silagem de sorgo a $90,28 \mathrm{~min} . / \mathrm{kg}$ de MS quando a fonte de volumoso foi $100 \%$ de bagaço de cana amonizado com ureia. A partir dos resultados observados, sugere-se que o tempo de mastigação da FDN teve uma tendência de aumento mais acentuada do que o tempo de mastigação da MS, aumentando em $73 \%$ quando a substituição foi por $100 \%$ de cana-de-açúcar e em $89,8 \%$ quando a substituição foi por $100 \%$ de bagaço (Tabela 5). 
Tabela 5: Consumo (kg/dia e min./kg), ruminação (min./kg) e mastigação (min./kg) da matéria seca (MS) e da fibra em detergente neutro (FDN), em função dos níveis de substituição da silagem de sorgo pela cana-de-açúcar ou bagaço de cana amonizado (B.A.) com ureia

\begin{tabular}{|c|c|c|c|c|c|}
\hline \multirow{2}{*}{ Variável } & \multirow{2}{*}{ Volumoso } & \multicolumn{4}{|c|}{ Níveis de Substituição, \% } \\
\hline & & 0 & 30 & 70 & 100 \\
\hline \multicolumn{6}{|c|}{ Consumo } \\
\hline \multirow{2}{*}{$\min . / \mathrm{kg} \mathrm{MS}$} & Cana & & 23,92 & 26,09 & 26,56 \\
\hline & B.A. & & 26,24 & 27,40 & 26,67 \\
\hline \multirow{2}{*}{$\mathrm{min} . / \mathrm{kg}$ FDN } & Cana & \multirow{2}{*}{43,36} & 55,65 & 68,77 & 79,43 \\
\hline & B.A. & & 57,36 & 62,70 & 70,59 \\
\hline \multicolumn{6}{|c|}{ Ruminação } \\
\hline \multirow{2}{*}{$\min . / \mathrm{kg} \mathrm{MS}$} & Cana & \multirow{2}{*}{39,54} & 39,94 & 42,11 & 46,36 \\
\hline & B.A. & & 39,39 & 49,28 & 63,62 \\
\hline \multirow{2}{*}{$\min . / k g$ FDN } & Cana & \multirow{2}{*}{82,53} & 92,93 & 111 & 138,61 \\
\hline & B.A. & & 86,11 & 112,79 & 168,40 \\
\hline \multicolumn{6}{|c|}{ Mastigação } \\
\hline \multirow{2}{*}{$\min . / \mathrm{kg} M S$} & Cana & \multirow{2}{*}{60,32} & 63,86 & 68,20 & 72,92 \\
\hline & B.A. & & 65,64 & 76,68 & 90,28 \\
\hline \multirow{2}{*}{$\min . / k g$ FDN } & Cana & \multirow{2}{*}{125,89} & 148,57 & 179,77 & 218,04 \\
\hline & B.A. & & 143,49 & 175,49 & 238,99 \\
\hline
\end{tabular}

De acordo com Van Soest (1994), a atividade de mastigação tem um importante papel no consumo e digestão de forragens, influenciando a taxa de secreção salivar, solubilizando os nutrientes, quebrando e reduzindo o tamanho das partículas e expondo os nutrientes para colonização e aumentando a taxa de passagem da digesta. Isto sugere uma maior dificuldade dos animais digerirem a fibra presente na cana-de-açúcar e principalmente no bagaço de cana amonizado.

A partir dos resultados da Tabela 6 para a eficiência da alimentação, dada pela ingestão em kg de MS/hora, inferese que, à medida que se aumenta o nível de substituição da silagem de sorgo por cana-de-açúcar, a eficiência diminuía. Para o bagaço de cana, esta tendência se mostra mais equânime, talvez devido ao alto teor de matéria seca presente no bagaço. No entanto, para a ingestão de $\mathrm{kg}$ de FDN/hora, a inferência é que, para ambos volumosos substitutos, quando se aumentam os níveis de substituição, a eficiência de consumo de FDN reduzia (Tabela 6).

Mendes Neto et al. (2007) trabalhando com novilhas mestiças, verificaram aumento da eficiência de alimentação em gramas de MS/hora com a substituição do feno de tifton pela polpa de citros, devido à diminuição do teor de FDN na dieta. Missio et al. (2010), ao avaliarem o comportamento ingestivo de tourinhos em confinamento, com níveis crescentes de concentrado, verificaram que quando os animais recebem níveis mais altos de concentrado (79\%), eles apresentam melhor eficiência de alimentação e ruminação. Segundo Van Soest (1994), o resultado das interações do metabolismo animal com as propriedades físicas e químicas dos alimentos interfere no consumo animal.

Silva et al. (2005) não observaram aumento significativo no consumo de matéria seca em g/ dia pelo aumento do teor de bagaço de mandioca na dieta de bovinos em diferentes níveis de substituição à silagem de capim-elefante. No entanto, estes autores observaram que o consumo de FDN decresceu linearmente à medida que se aumentava o teor de bagaço de mandioca, sendo que a eficiência de alimentação expressa em gramas de MS e em gramas de FDN ingeridas/ hora, não foi afetada pelos diferentes tratamentos. Os valores encontrados por esses autores para a ingestão de $\mathrm{MS} / \mathrm{h}$ e FDN/h foram inferiores em relação aos obtidos neste trabalho. Com relação à eficiência de ruminação, os valores encontrados por esses autores também foram inferiores aos aqui mostrados (Tabela 6). Esta divergência pode ser explicada pela diferença na capacidade de consumo dos animais, sendo que no trabalho de Silva et al. (2005) era novilhas mestiças e neste trabalho novilhos Nelore em fase de terminação.

Quanto a eficiência de ruminação, tanto para $\mathrm{kg}$ $\mathrm{MS} / \mathrm{h}$ quanto para $\mathrm{kg} \mathrm{FDN} / \mathrm{h}$, infere-se que houve uma tendência de redução à medida que se aumentavam os níveis de substituição, tanto para a cana-de-açúcar quanto para o bagaço de cana amonizado. Neste caso, a quantidade de FDN ingerida $\mathrm{em} \mathrm{kg} /$ hora reduziu à metade. A despeito do alto teor de FDN presente na silagem de sorgo, e às tendências apresentadas para a eficiência de alimentação e ruminação, sugere-se que este

Tabela 6: Eficiências de alimentação (EA) e de ruminação (ER) para matéria seca (MS) e fibra em detergente neutro (FDN), em função dos níveis de substituição da silagem de sorgo pela cana-de-açúcar ou bagaço de cana amonizado (BA) com ureia

\begin{tabular}{clrrrr}
\hline \multirow{2}{*}{ Variável } & \multirow{2}{*}{ Volumoso } & \multicolumn{5}{c}{ Níveis de Substituição, \% } \\
& \multicolumn{5}{c}{ Consumo } \\
\hline EA & Cana & 30 & 70 & 100 \\
\hline kg MS/hora & BA & 2,89 & 2,51 & 2,30 & 2,26 \\
EA & Cana & & 2,29 & 2,19 & 2,25 \\
kg FDN/hora & BA & 1,38 & 1,08 & 0,87 & 0,76 \\
ER & Cana & & 1,05 & 0,96 & 0,85 \\
kg MS/hora & BA & 1,52 & 1,50 & 1,42 & 1,29 \\
ER & Cana & & 0,65 & 1,22 & 0,94 \\
kg FDN/hora & BA & 0,73 & 0,70 & 0,53 & 0,43 \\
\hline
\end{tabular}


volumoso possui uma FDN de melhor qualidade. A relação entre a quantidade de FDA e FDN da silagem de sorgo também atesta que há maior quantidade de energia disponível para os processos metabólicos efetuados pelas bactérias do rúmen, já que a fração solúvel em ácido inclui hemicelulose e proteínas da parede celular, enquanto o resíduo desta extração (FDA) recupera a lignina, celulose e frações menos digestíveis dos não carboidratos.

Não foram verificadas diferenças significativas $(P>0,05)$ para o número de refeições diárias e duração da refeição com a substituição da silagem de sorgo pela cana-deaçúcar ou pelo bagaço de cana amonizado (Tabela 7). Todavia, o número de ciclos de ruminação (Figura 2) e ócio (Figura 3), assim como a duração dos ciclos de ruminação e ócio (Figura 4), sofreram influência $(P<0,05)$ dos níveis de substituição. O número de ciclos de ruminação apresentou comportamento quadrático em função dos níveis de substituição da silagem de sorgo pela cana, apresentando ponto de máximo ao nível de 51,5\% de substituição. Já a substituição da silagem de sorgo pelo bagaço amonizado implicou efeito linear sob esta variável, havendo aumento no número de ciclos de ruminação com o aumento dos níveis de substituição. Quanto ao número de períodos de ócio e a duração dos ciclos de ruminação e ócio, não houve interação dos níveis de substituição com os volumosos substitutos. Entretanto, a substituição da silagem de sorgo pela cana ou pelo bagaço implicou comportamento quadrático destas variáveis. Para o número de períodos de ócio, o ponto de máximo foi ao nível de $46,55 \%$ de substituição. Já para a duração dos ciclos de ruminação e ócio, os pontos de mínimo foram, respectivamente, aos níveis de 63,1 e 43,17\% de substituição (Tabela 7).

As variações observadas no número de ciclos de ruminação e duração destes ciclos podem estar relacionadas com as eficiências de ruminação da MS e da FDN, que tenderam a decrescer com o aumento dos níveis de substituição, de forma mais pronunciada, quando o volumoso substituto à silagem de sorgo era o bagaço de cana amonizado. Freitas et al. (2010), ao compararem o comportamento ingestivo de novilhos em confinamento, alimentados com dietas a base de silagem de milho ou silagem de girassol, correlacionaram um maior tempo de refeição para os animais alimentados com silagem de milho com as maiores eficiências de ruminação da MS e FDA alcançadas com esta dieta em relação à dieta à base de silagem de girassol. De acordo com Dado e Allen (1995), a maior taxa de ingestão da MS está relacionada com o aumento na taxa de passagem da fibra nos compartimentos ruminais e o menor tempo de retenção da FDN.

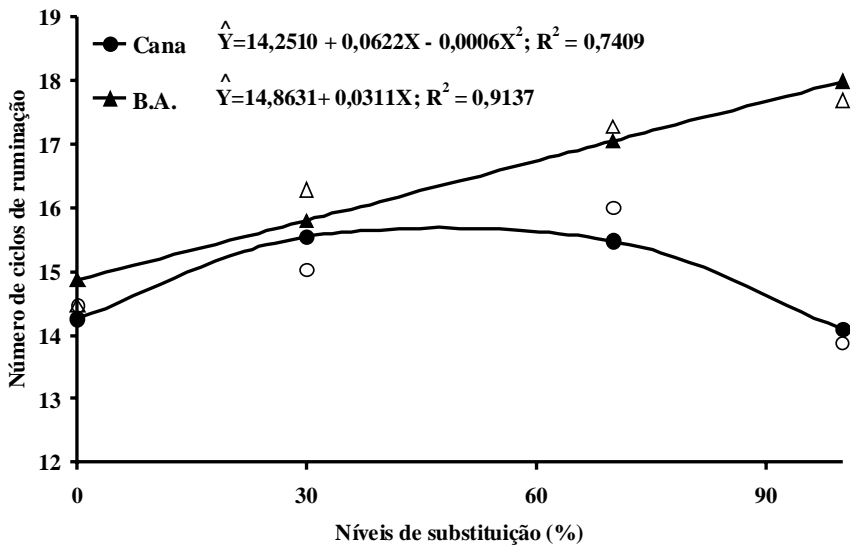

Figura 2: Número de ciclos de ruminação de novilhos Nelore confinados com diferentes níveis de substituição da silagem de sorgo por cana ou bagaço de cana amonizado com ureia (B.A.)

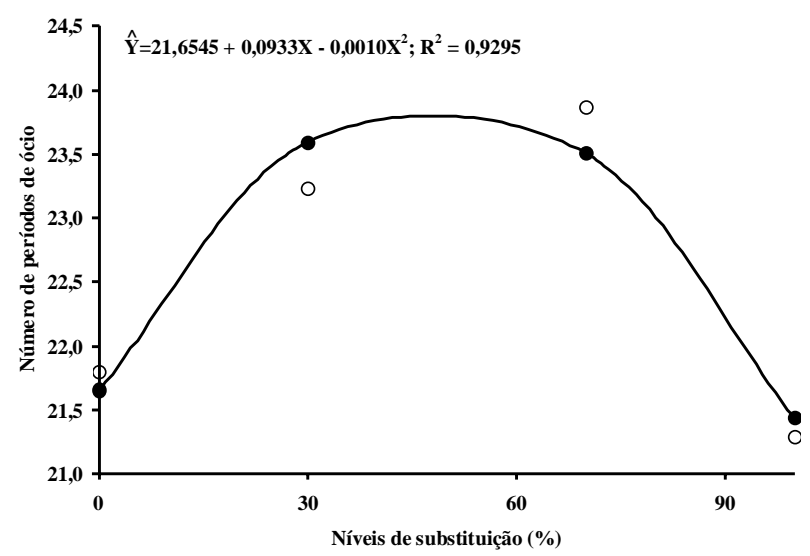

Figura 3: Número de períodos de ócio de novilhos Nelore confinados com diferentes níveis de substituição da silagem de sorgo por cana ou bagaço de cana amonizado com ureia. 


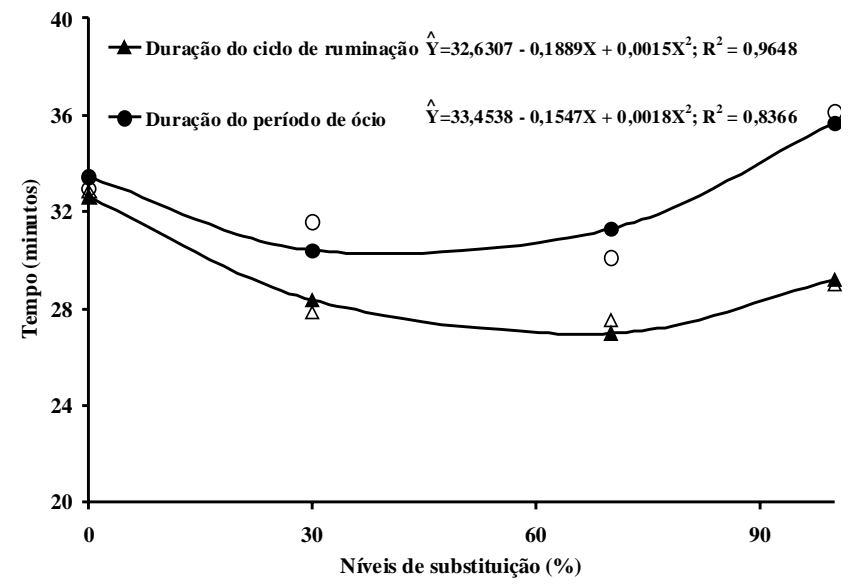

Figura 4: Duração do ciclo de ruminação e do período de ócio de novilhos Nelore confinados com diferentes níveis de substituição da silagem de sorgo por cana ou bagaço de cana amonizado com ureia.

\section{Referências}

ABRAHÃO, J. S.; MARQUES, J. A.; PRUDENTE, A. C.; GROFF, A. M.; LANÇANOVA, J. J. A. G.; ROSA, L. J. Comportamento ingestivo de tourinhos mestiços submetidos a dietas com diferentes volumosos confinados aos pares. In: REUNIÃO ANUAL DA SOCIEDADE BRASILEIRA DE ZOOTECNIA, 43. 2006. Anais... João Pessoa: SBZ, 2006. 1 CD-ROM.

ASSOCIATION OF ANALITICAL CHEMIST. Official methods of analysis. 15. ed., Arlington : [s.n.],1990. 117 p.

BARROS, R.C.; ROCHA JÚNIOR, V.R.; SOUZA, A.S.; FRANCO, M.O.; OLIVEIRA, T.S.; MENDES, G.A.; PIRES, D.A.A.; SALES, E.C.J.; CALDEIRA, L.A. Viabilidade econômica da substituição da silagem de sorgo por cana-de-açúcar ou bagaço de cana amonizado com ureia no confinamento de bovinos. Revista Brasileira de Saúde e Produção Animal, v. 11, n. 3, p. 555-569, 2010.

BÜRGER, P.J.; PEREIRA, J.C.; QUEIROZ, A.C.; SILVA, J.F.C.; VALADARES FILHO, S.C.; CECON, P.R.; CASALI, A.D.P. Comportamento ingestivo em bezerros holandeses alimentados com dietas contendo diferentes níveis de concentrado. Revista Brasileira de Zootecnia, v. 29, n.1, p. 236-242, 2000.

DADO, R.G.; ALLEN, M.S. Intake limitations, feeding behavior, and rumen function of cows challenged with rumen fill from dietary fiber or inert bulk. Journal of Dairy Science, v.78, n.1, p.118-133, 1995.

FREITAS, L. S., SILVA, J. H. S., SEGABINAZZI, L. R., SILVA, V.S., ALVES FILHO, D.C., BRONDANI, I. L. Substituição da silagem de milho por silagem de girassol na dieta de novilhos em confinamento: comportamento ingestivo. Revista Brasileira de Zootecnia, Viçosa, v. 39, n. 1, p. 225-232, 2010.

GONÇALVES, A. L.; LANA, R. P.; RODRIGUES, M. T.; VIEIRA, R. A. M.; QUEIROZ, A. C.; HENRIQUE, D. S. Padrão nictemeral do $\mathrm{pH}$ ruminal e Comportamento alimentar de cabras leiteiras alimentadas com dietas contendo diferentes relações volumoso:concentrado. Revista Brasileira de Zootecnia, Viçosa, v. 30, n. 6, p.1886-1892, 2001.

MARQUES, J. A.; CALDAS NETO,S.F.; GROFF, A. M.; SIMONELLI, S. M.; CORASA, J.; ROMERO, L.; ZAWADSKI, F.; ARAÚJO, P. F.5ITO, R. H.; ZAWADZKI, F.; MAGGIONI, D.; BEZERRA, G. A.; PEDROSO, P. H. B.; PRADO, I. N. Comportamento de bovinos mestiços em confinamento com e sem acesso à sombra durante o período de verão. Campo Digital, Campo Mourão, v. 1, n. 1, p. 54-59, 2006.

MENDES NETO, J.; CAMPOS, J. M. S., VALADARES FILHO, S. C., LANA, R. P., QUEIROZ, A.C., EUCLYDES, R. F. Comportamento ingestivo de novilhas leiteiras alimentadas com polpa cítrica em substituição ao feno de capim-tifton 85. Revista Brasileira de Zootecnia, v. 36, n. 3, p. 618-627, 2007.

\section{Conclusões}

O aumento do teor de cana-de-açúcar na dieta de novilhos Nelore confinados, em diferentes níveis de substituição à silagem de sorgo, não provocou alterações nos tempos de alimentação, ruminação e ócio dos animais. Já a substituição da silagem de sorgo por bagaço de cana-de-açúcar amonizado com ureia provocou alterações no comportamento ingestivo, reduzindo o tempo de alimentação e aumentando o tempo de ruminação dos animais. O número de ciclos de ruminação e a duração destes ciclos foram afetados por ambos volumosos substitutos.

\section{Agradecimentos}

Ao Banco do Nordeste/Fundeci pelo apoio financeiro; à Colonial Agropecuária Ltda, pela concessão dos animais; à FAPEMIG e ao CNPq pelo auxílio com bolsas.

MENDONÇA, S.S.; CAMPOS, J. M. S.; VALADARES FILHO, S. C. VALADARES, R. F. D.; SOARES, C. A.; LANA, R. P.; QUEIROZ, A. C.; ASSIS, A. J.; PEREIRA, M. L. A.Comportamento ingestivo de vacas leiteiras alimentadas com dietas à base de cana-de-açúcar ou silagem de milho. Revista Brasileira de Zootecnia, v. 33, n. 3, p. 723-728, 2004.

MIRANDA, L. F.; QUEIROZ, A. C.; VALADARES FILHO, S. C.; CECON, P. R.; PEREIRA, E. S.; CAMPOS, J. M. S.; LANNA, R. P.; MIRANDA, J. R. Comportamento ingestivo de novilhas leiteiras alimentadas com dietas à base de cana-de-açúcar. Revista Brasileira de Zootecnia, v. 28, n. 3, p. 614-620, 1999.

MISSIO, R. L., BRONDANI, I. L., ALVES FILHO, D.C., SILVEIRA, M. F., FREITAS, L. S., RESTLE, J. Comportamento ingestivo de tourinhos terminados em confinamento, alimentados com diferentes níveis de concentrado na dieta. Revista Brasileira de Zootecnia, v. 39, n. 7, p. 1571-1578, 2010.

PEREIRA, E. S., MIZUBUTI, I. Y., RIBEIRO, E. L. A., VILLARROEL, A. B. S., PIMENTEL, P. G. Consumo, digestibilidade aparente dos nutrientes e comportamento ingestivo de bovinos da raça Holandesa alimentados com dietas contendo feno de capim-tifton 85 com diversos tamanhos de partícula. Revista Brasileira de Zootecnia, v. 38, n. 1, p. 190-195, 2009. PEREIRA, J. C., CUNHA, D. N. F. V., CECON, P. R., FARIA, E. S. Comportamento ingestivo e taxa de passagem de partículas em novilhas leiteiras de diferentes grupos genéticos submetidas a dietas com diferentes níveis de fibra. Revista Brasileira de Zootecnia, v. 36, n. 6, p. 2134-2142, 2007. RABELO, M. M. A.;PIRES, A. V.;TURINO, V.; NUSSIO, L. G.; FERNANDES, J. J. R. Comportamento ingestivo de novilhos de corte alimentados com dieta à base de bagaço de cana-de-açúcar tratado sob pressão e vapor e in natura. In: REUNIÃO DA SOCIEDADE BRASILEIRA DE ZOOTECNIA, 38., 2001. Anais... Brasília, DF: SBZ, 2001. 1 CD-ROM. SAS INSTITUTE. SAS/STAT User's guide. Cary, NC: STATS, 2000.

SILVA, R. R.; CARVALHO, G. G. P.; FRANCO, I. L.; VELOSO, C. M.; CHAVES, M. A.; BONOMO, P.; PRADO, I. N.; ALMEIDA, V. S.Comportamento ingestivo de novilhas mestiças de Holandês $x$ Zebu confinadas. Archivos de Zootecnia, v. 54, n. 205, p. 85, 2005.

TILLEY, J.M.A.; TERRY, R.A.A. Two-stage technique for the in vitro digestion of forage crops. Journal British Grassland Society, v. 18, n. 2, p. 104-111, 1963.

VALADARES FILHO, S. C.; PAULINO, P. V. R.; MAGALHÃES, K .A. Exigências Nutricionais de Zebuínos e Tabelas de Composição e Alimentos BR-Corte. Viçosa: UFV, 2006, 142 p.

VAN SOEST, P.J. Nutritional ecology of the ruminant. Ithaca: Cornell University Press, 1994, $477 \mathrm{p}$.

VAN SOEST, P.J.; ROBERTSON, J.B.; LEWIS, B.A. Methods for dietary fiber, neutral detergent fiber and non-starch polysaccharides in relation to animal nutrition. Journal of Animal Science, v. 74, n. 10, p. 35833597, 1991. 